\title{
Retrospective analysis of 1,641 cases of classic fever of unknown origin
}

\author{
Guanyu Zhou, Ying Zhou, Cejun Zhong, Hui Ye, Zhenzhen Liu, Yanbin Liu, Guangmin Tang, \\ Junyan Qu, Xiaoju Lv
}

Center of Infectious Diseases, West China Hospital, Sichuan University, Chengdu, China

Contributions: (I) Conception and design: G Zhou; (II) Administrative support: X Lv; (III) Provision of study materials or patients: X Lv; (IV) Collection and assembly of data: G Zhou, Y Zhou; (V) Data analysis and interpretation: G Zhou; (VI) Manuscript writing: All authors; (VII) Final approval of manuscript: All authors.

Correspondence to: Xiaoju Lv. Center of Infectious Diseases, West China Hospital, Sichuan University, Chengdu, China. Email: lvxj3369@163.com.

Background: Fever of unknown origin (FUO) is commonly defined as fever higher than $38.3{ }^{\circ} \mathrm{C}$ on several occasions during at least 3 weeks with uncertain diagnosis after a number of obligatory investigations. It is a special type of fever and a common disease in internal medicine. However, due to its complex etiology, lack of characteristic clinical manifestations, and insufficient laboratory examination indicators, it often baffles clinicians in diagnosis. We herein present a study of the etiological factors and clinical features of classic fever of unknown origin (FUO) to provide help for related clinical diagnosis and treatment.

Methods: A total of 1,641 cases of patients with classic FUO hospitalized in West China Hospital of Sichuan University between January 1, 2011 and December 31, 2017, were collected, and the etiological factors of classic FUO were analyzed. A special effort was made to explore and screen the laboratory indicators related to infectious diseases, and the above data were compared with the clinical features of tuberculosis and lymphoma, which are difficult to diagnose.

Results: Among the 1,641 patients, 1,504 were finally diagnosed through various types of examination or diagnostic methods, and the diagnosis rate was 91.65\%. Among all the causes of the 1,641 cases of FUO, $48.69 \%$ [799] were infectious diseases, of which tuberculosis was the most common, accounting for $19.50 \%$ [320]. Connective tissue diseases were responsible for $19.26 \%$ [316] of cases, of which adult-onset Still's disease (AOSD) was the most common, comprising 89 (5.42\%) of the cases; $16.94 \%$ [278] were neoplastic diseases, and lymphoma $(143,8.71 \%)$ cases, was the most common malignant tumor; $6.76 \%$ [111] were other diseases; and in $8.35 \%$ [137] of cases, the cause was unclear. Through comparative analysis of tuberculosis and lymphoma, no significant differences were found between the symptoms, signs, and non-specific routine examination results of the two diseases. The diagnosis of these diseases was more dependent on tuberculosisrelated examinations and pathological examinations.

Conclusions: Infectious diseases are the principal cause of classic FUO, in which tuberculosis accounts for a large proportion. Non-infectious diseases that cause FUO are mainly connective tissue diseases and malignant tumors. Of the various causes of classic FUO, tuberculosis and lymphoma are relatively difficult to diagnose. In most cases, the causes of classic FUO can be ascertained.

Keywords: Fever of unknown origin (FUO); etiology; retrospective analysis

Submitted Mar 27, 2020. Accepted for publication Jun 09, 2020.

doi: $10.21037 /$ atm-20-3875

View this article at: http://dx.doi.org/10.21037/atm-20-3875 


\section{Introduction}

Fever of unknown origin (FUO) is a distinct type of fever that is commonly encountered in internal medicine. However, because of its complex etiology, lack of characteristic clinical manifestations, and insufficient laboratory examination indicators, its diagnosis often presents a challenge for clinicians. Petersdorf and Beeosn put forward the following criterion for FUO: a fever higher than $38.3{ }^{\circ} \mathrm{C}\left(101{ }^{\circ} \mathrm{F}\right)$ on several occasions that persists without diagnosis for at least 3 weeks; and at least 1 week's investigation in hospital. The advantage of this diagnostic criterion is that it eliminates shortterm self-healing and unexplained acute fever, certain selflimiting viral infections, and functional fever characterized by hypothermia. Symptoms meeting the criterion are referred to as classic FUO (1). In 1991, Durack and street classified fever of unknown origin into four types: classical type, neutropenic type, hospital acquired type and HIV related type. The disease spectrum of different types of FUO is quite different (2). Our study is only included in the classic type of FUO, which is similar to the standard set by Petersdorf and Beeson in 1961 . In recent years, there are many studies on the etiology of fever of unknown origin. Recently, large sample studies in Asia are from Japan (3). Our study has a larger sample size and a longer time span than this study, and it is from developing countries. The disease distribution is quite different from the previous study, so we report it.

In this retrospective study, a total of 1,641 cases of patients with classic FUO hospitalized in West China Hospital of Sichuan University between January 1, 2011 and December 31, 2017, were collected, and the etiological factors of classic FUO were analyzed and compared with the clinical features of tuberculosis and lymphoma, which are difficult to diagnose, to provide guidance for related clinical diagnosis. We present the following article in accordance with the STROBE reporting checklist (available at http://dx.doi.org/10.21037/atm-20-3875).

\section{Methods}

\section{Clinical data}

We retrospectively collected cases of patients hospitalized with fever in West China Hospital, Sichuan University between January 1, 2011 and December 31, 2017 and selected the medical records of patients with classic FUO. The selected patients, whose ages ranged from 14 years old upwards, had each been hospitalized for more than a week with a fever higher than $38.3^{\circ} \mathrm{C}\left(101{ }^{\circ} \mathrm{F}\right)$ that had occurred on several occasions and had persisted for at least 21 days. Patients diagnosed with HIV infection before hospitalization, patients with immunodeficiency disorders, and pregnant women were screened out. Finally, 1,641 cases of classic FUO were selected for analysis.

\section{Diagnostic methods}

The diagnosis of FUO can be based on any of the following five criteria: (I) clinical manifestation and positive histopathological examination (including bone marrow examination) results; (II) clinical manifestation and obtained pathogenic evidence (the same strain or body fluid is detected in blood culture more than twice, with a pathogen found once or more); (III) clinical manifestation, obtained radiographic evidence and one piece of pathogenic evidence; (IV) clinical manifestation, positive antigen detection once or more, and an observed therapeutic reaction; (V) the diagnostic criteria for a certain disease are met. The clinical diagnostic criteria are: in the case of the diagnostic criteria not being met, clinical manifestation shall be observed, radiographic evidence or general laboratory evidence shall be obtained, and therapeutic reaction shall be observed.

This study was conducted in accordance with the Declaration of Helsinki and was approved by Ethics Committee of West China Hospital of Sichuan University. Because of the retrospective nature of the research, the requirement for informed consent was waived.

\section{Results}

\section{Brief introduction of the cases selected for study}

The 1,641 patients comprised 757 (46.13\%) males and 884 (53.87\%) females. Patients were aged under 20 in $10.60 \%$ [174] of cases, 20 to 39 in $36.14 \%$ [593] of cases, 40 to 59 in $30.23 \%$ [496] of cases, and 60 or older in $23.03 \%$ [378] of cases. Of the 1,641 cases of classic FUO, 91.65\% $[1,504]$ were diagnosed. The causes were ascertained in $65.69 \%$ [1,078] of cases, $25.96 \%$ [426] cases were clinically diagnosed, and the causes of $8.35 \%$ [137] of cases were unclear. The causes of the various cases of FUO are shown in Table 1. The percentages of causes ranked by gender and age are shown in Tables 2,3 and Figure 1, respectively. The duration of FUO varies with different diseases. When no diagnosis is made, the duration is calculated from the onset of fever to the discharge time. The durations of the various cases of FUO and the percentage of each cause are shown 
Table 1 Causes of the 1,641 cases of FUO

\begin{tabular}{|c|c|c|}
\hline Cause of FUO & $\begin{array}{l}\text { No. of } \\
\text { cases }\end{array}$ & $\begin{array}{c}\text { Percentage } \\
(\%)\end{array}$ \\
\hline Infectious diseases & 799 & 48.69 \\
\hline Bacterial infections & 591 & 36.01 \\
\hline Tuberculosis & 320 & 19.50 \\
\hline Septicemia & 117 & 7.13 \\
\hline Infective endocarditis & 47 & 2.86 \\
\hline Biliary tract infection & 32 & 1.95 \\
\hline Pulmonary infection & 15 & 0.91 \\
\hline Urinary tract infection & 13 & 0.79 \\
\hline Peritonitis & 11 & 0.67 \\
\hline Liver abscess & 7 & 0.43 \\
\hline Brucellosis & 7 & 0.43 \\
\hline Abdominal abscess & 6 & 0.36 \\
\hline Renal abscess & 5 & 0.30 \\
\hline $\begin{array}{l}\text { Non-tuberculosis mycobacteria } \\
\text { infection }\end{array}$ & 4 & 0.24 \\
\hline Chronic tonsillitis & 3 & 0.18 \\
\hline Typhoid & 3 & 0.18 \\
\hline Retropharyngeal abscess & 1 & 0.06 \\
\hline Viral infections & 168 & 10.24 \\
\hline Epstein-Barr virus & 83 & 5.06 \\
\hline Cytomegalovirus & 33 & 2.01 \\
\hline Herpes simplex virus & 12 & 0.73 \\
\hline Viral meningitis & 9 & 0.55 \\
\hline HIV & 8 & 0.49 \\
\hline Rubella & 3 & 0.18 \\
\hline Parvovirus & 1 & 0.06 \\
\hline Other viral infections & 19 & 1.16 \\
\hline Invasive fungal infections & 15 & 0.91 \\
\hline Pulmonary aspergillosis & 7 & 0.43 \\
\hline Histoplasmosis & 5 & 0.30 \\
\hline Aspergillus sinusitis & 3 & 0.18 \\
\hline Parasitic infections & 16 & 0.98 \\
\hline Kala-azar & 11 & 0.67 \\
\hline Paragonimiasis & 2 & 0.12 \\
\hline Toxoplasma gondii & 2 & 0.12 \\
\hline Malaria & 1 & 0.06 \\
\hline Other pathogenic infections & 9 & 0.55 \\
\hline Mycoplasmal pneumonia & 7 & 0.43 \\
\hline Tsutsugamushi & 2 & 0.12 \\
\hline
\end{tabular}

Table 1 (continued)

\begin{tabular}{|c|c|c|}
\hline Cause of FUO & $\begin{array}{l}\text { No. of } \\
\text { cases }\end{array}$ & $\begin{array}{l}\text { Percentage } \\
(\%)\end{array}$ \\
\hline Connective tissue diseases & 316 & 19.26 \\
\hline AOSD & 89 & 5.42 \\
\hline Systemic lupus erythematosus & 31 & 1.89 \\
\hline Systemic vasculitis & 29 & 1.77 \\
\hline Necrotizing lymphadenitis & 28 & 1.71 \\
\hline Sjogren syndrome & 23 & 1.40 \\
\hline Polymyalgia rheumatica & 12 & 0.73 \\
\hline Dermatomyositis & 12 & 0.73 \\
\hline Rheumatoid arthritis & 11 & 0.67 \\
\hline Erythema nodosum & 9 & 0.55 \\
\hline Reactive arthritis & 8 & 0.49 \\
\hline Ankylosing spondylitis & 5 & 0.30 \\
\hline Autoimmune liver disease & 5 & 0.30 \\
\hline IgG4-related diseases & 5 & 0.30 \\
\hline Systemic sclerosis & 4 & 0.24 \\
\hline Polymyositis & 2 & 0.12 \\
\hline Behcet's disease & 2 & 0.12 \\
\hline Autoimmune encephalitis & 1 & 0.06 \\
\hline Rheumatic fever & 1 & 0.06 \\
\hline Mixed connective tissue disease & 18 & 1.10 \\
\hline $\begin{array}{l}\text { Undifferentiated connective tissue } \\
\text { disease }\end{array}$ & 21 & 1.28 \\
\hline Neoplastic diseases & 278 & 16.94 \\
\hline Lymphoma & 143 & 8.71 \\
\hline Leukemia & 61 & 3.72 \\
\hline Multiple myeloma & 31 & 1.89 \\
\hline Hepatoma & 12 & 0.73 \\
\hline Malignant histiocytosis & 11 & 0.67 \\
\hline Lung carcinoma & 7 & 0.43 \\
\hline Renal carcinoma & 4 & 0.24 \\
\hline Soft tissue sarcoma & 3 & 0.18 \\
\hline Prostate cancer & 3 & 0.18 \\
\hline Thyroid carcinoma & 2 & 0.12 \\
\hline Ovarian cancer & 1 & 0.06 \\
\hline Other diseases & 111 & 6.76 \\
\hline Undetermined & 137 & 8.35 \\
\hline Total & 1,641 & 100 \\
\hline
\end{tabular}

Table 1 (continued) 
Table 2 Percentages of causes of FUO ranked by gender

\begin{tabular}{|c|c|c|c|c|c|c|}
\hline Gender & Infectious diseases (\%) & Connective tissue diseases (\%) & Neoplastic diseases (\%) & Other diseases (\%) & Undetermined (\%) & Total \\
\hline Male & $439(58.11)$ & $107(14.13)$ & $127(16.67)$ & $40(5.28)$ & $44(5.81)$ & 757 \\
\hline Female & $360(40.73)$ & $209(23.64)$ & $151(17.08)$ & $71(8.03)$ & $93(10.52)$ & 884 \\
\hline Total & 799 (48.69) & $316(19.26)$ & $278(16.94)$ & $111(6.76)$ & $137(8.35)$ & 1,641 \\
\hline
\end{tabular}

FUO, fever of unknown origin.

Table 3 Percentages of causes of FUO ranked by age

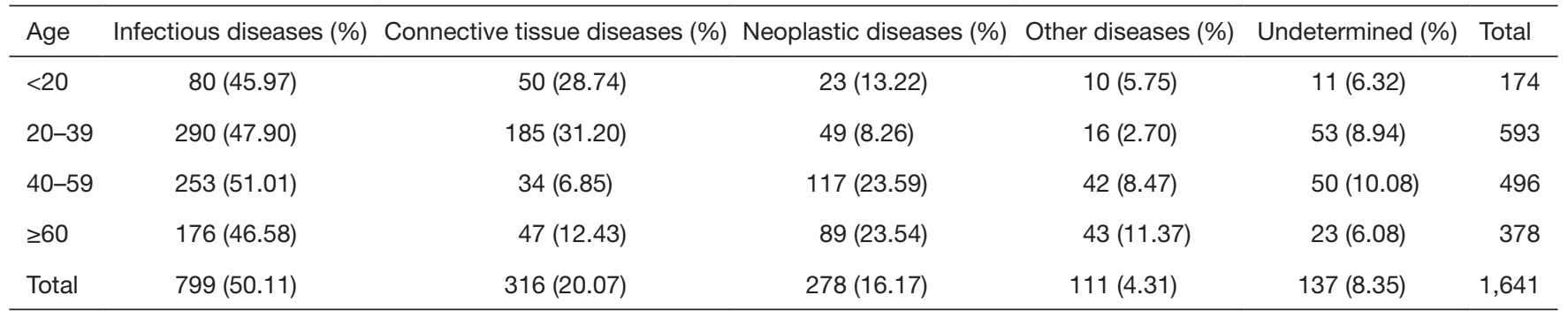

FUO, fever of unknown origin.

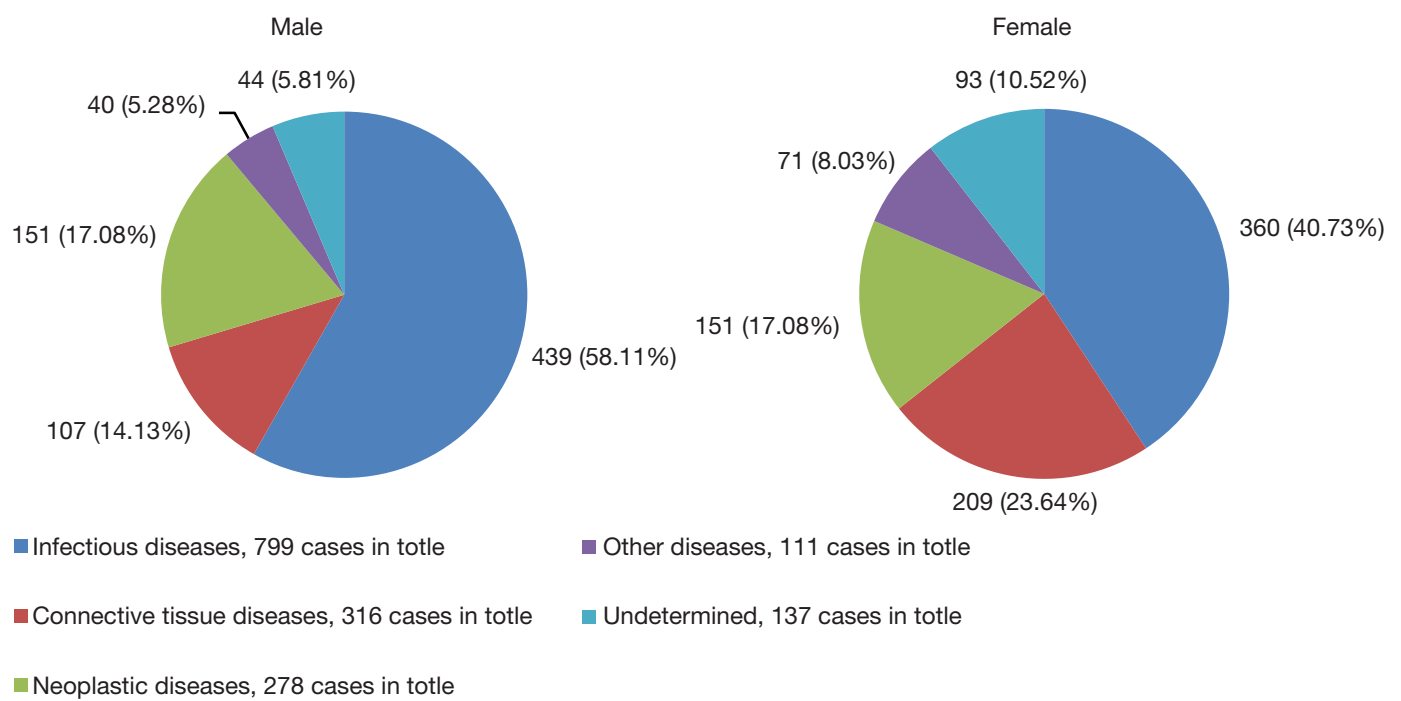

Figure 1 The relationship between the distribution of etiology and gender in patients with fever of unknown origin.

in Table 4. The diagnosis of different diseases often relies on different diagnostic methods; the methods by which the different diseases were finally diagnosed are shown with their percentage in Table 5 .

\section{Comparison between the clinical data of lymphoma and tuberculosis}

The results of our study showed that tuberculosis was the most common infectious disease that caused FUO, while the most common non-infectious disease that caused FUO was lymphoma; these two diseases took a long time to diagnose. Other than long-term fever, the clinical manifestations of lymphoma are not usually characteristic, which presents many difficulties in diagnosing this disease. In this respect, tuberculosis is similar to lymphoma. Lymphoma and tuberculosis are the neoplastic and infectious diseases, respectively, that are most challenging to distinguish 
Table 4 Durations of the various cases of FUO and the percentage of each cause

\begin{tabular}{|c|c|c|c|c|c|c|}
\hline $\begin{array}{l}\text { Duration of FUO } \\
\text { (days) }\end{array}$ & $\begin{array}{c}\text { Infectious diseases } \\
(\%)\end{array}$ & $\begin{array}{l}\text { Connective tissue diseases } \\
\qquad(\%)\end{array}$ & $\begin{array}{c}\text { Neoplastic diseases } \\
(\%)\end{array}$ & $\begin{array}{l}\text { Other diseases } \\
(\%)\end{array}$ & $\begin{array}{l}\text { Undetermined } \\
\qquad(\%)\end{array}$ & Total \\
\hline $21-30$ & $239(46.96)$ & $135(26.52)$ & $62(12.18)$ & 62 (12.18) & $11(2.16)$ & 509 \\
\hline $31-60$ & $230(42.83)$ & 93 (17.32) & 166 (30.91) & $41(7.64)$ & 7 (1.30) & 537 \\
\hline $60-90$ & $162(59.79)$ & $24(8.85)$ & $46(16.97)$ & 8 (2.95) & 31 (11.44) & 271 \\
\hline Total & 799 (48.69) & $316(19.26)$ & 278 (16.94) & $111(6.76)$ & $137(8.35)$ & 1,641 \\
\hline
\end{tabular}

FUO, fever of unknown origin.

Table 5 Methods by which the diseases were diagnosed

\begin{tabular}{|c|c|c|c|c|c|}
\hline Type of disease & $\begin{array}{c}\text { Laboratory investigation } \\
\text { (\%) }\end{array}$ & $\begin{array}{c}\text { Radiographic investigation } \\
(\%)\end{array}$ & $\begin{array}{c}\text { Invasive investigation } \\
(\%)\end{array}$ & $\begin{array}{c}\text { Diagnostic treatment } \\
(\%)\end{array}$ & Total \\
\hline Infectious diseases & $257(32.16)$ & $216(27.03)$ & $90(11.26)$ & $236(29.55)$ & 799 \\
\hline Connective tissue diseases & $164(51.90)$ & $0(0)$ & $74(23.42)$ & 78 (24.68) & 316 \\
\hline Neoplastic diseases & $0(0)$ & $53(19.06)$ & 225 (80.94) & $0(0)$ & 278 \\
\hline Total & $440(29.25)$ & $296(19.68)$ & $394(26.19)$ & $374(24.88)$ & 1,504 \\
\hline
\end{tabular}

Note: diagnostic treatment includes drug discontinuance and clinical observation.

between. In a large proportion of cases, either tuberculosis or lymphoma is the underlying cause of a fever lasting more than 90 days, which offers a glimpse into the difficulty of their diagnosis. The clinical manifestations of tuberculosis and lymphoma also have many similarities. For instance, in some tuberculosis and lymphoma patients, the spleen or lymph nodes are enlarged, and the peak body temperature is high, which can make distinguishing between the two difficult. We conducted a comparative study of the clinical manifestations of the two diseases, as shown in Table 6.

Through the comparison between the above basic clinical manifestations and laboratory investigation, no sufficient factors $(\mathrm{P}>0.05)$ suggestive of lymphoma could be found. Therefore, specific investigations to distinguish lymphoma from tuberculosis are called for.

\section{Discussion}

Our retrospective analysis showed infectious diseases to be the most common cause of classic FUO, followed by connective tissue diseases. These results are consistent with most previous Chinese and overseas studies (4-7). The causes of FUO are disease related. In Our retrospective analysis, while the incidence of neoplastic disease was not significantly correlated with gender, the incidence of connective tissue disease was higher in women, and the incidence of infectious disease was more common in men. There was no significant difference in the incidence of infectious disease across all age groups. Patients under 40 years of age were more likely to experience connective tissue disease, while the incidence of neoplastic disease was increased in patients over 40 years old. The time from onset to final confirmation of the cause of FUO was also varies. This retrospective study found no association between the diagnoses of infectious diseases in West China Hospital and fever duration; however, foreign studies have shown that the time required to diagnose an infectious disease is usually short (5). The lung infections and biliary tract infections involved in this study could not be diagnosed less than 30 days after the onset of fever. This may be explained by the uneven distribution of primary medical resources in China and Chengdu's location in the Western part of China, which means some patients are unable to access timely medical treatment. Generally, after hospitalization, 
Table 6 Comparison between the clinical data of lymphoma and tuberculosis patients

\begin{tabular}{|c|c|c|c|}
\hline Variable & Lymphoma (n=86) & Tuberculosis $(n=174)$ & $P$ value \\
\hline Gender (male) ${ }^{2}$ & 42 [48.3\%] & $91[52.87 \%]$ & 0.394 \\
\hline Duration of fever (days) ${ }^{3}$ & $50[25-380]$ & $49[23-100]$ & 0.342 \\
\hline Highest body temperature $\left({ }^{\circ} \mathrm{C}\right)^{3}$ & $39.0[38.4-40.1]$ & $39.0[38.3-39.8]$ & 0.451 \\
\hline Intermittent fever & 21 & 53 & \\
\hline Remittent fever & 42 & 104 & \\
\hline Irregular fever & 23 & 17 & \\
\hline Duration of fever ${ }^{4}$ & & & 0.063 \\
\hline 18:00-6:00 (next day) & 23 & 41 & \\
\hline Irregular & 10 & 19 & \\
\hline Chills $^{4}$ & & & 0.071 \\
\hline No & 31 & 74 & \\
\hline Yes & 55 & 100 & \\
\hline Shivering $^{4}$ & & & 0.195 \\
\hline No & 62 & 138 & \\
\hline Yes & 24 & 36 & \\
\hline Yes & 17 & 45 & \\
\hline WBC $\left(\times 10^{9} / \mathrm{L}\right)^{3}$ & 6.27 [1.27-12.65] & 8.44 [3.22-15.02] & 0.071 \\
\hline $\mathrm{HB}(\mathrm{g} / \mathrm{L})^{3}$ & 105 [74-129] & $102[76-132]$ & 0.174 \\
\hline $\operatorname{PLT}\left(\times 10^{9} / \mathrm{L}\right)^{3}$ & 211 [89-337] & 206 [81-382] & 0.067 \\
\hline $\operatorname{ESR}(\mathrm{mm} / \mathrm{h})^{3}$ & $29[2-120]$ & $62[15-120]$ & 0.057 \\
\hline $\mathrm{CRP}(\mathrm{mg} / \mathrm{dL})^{3}$ & $66.8[1.73-166]$ & $59.2[10.4-169]$ & 0.054 \\
\hline $\mathrm{PCT}(\mathrm{ng} / \mathrm{mL})^{3}$ & $0.52[0.04-3.16]$ & $0.66[0.04-4.43]$ & 0.192 \\
\hline $\mathrm{LDH}(\mathrm{U} / \mathrm{L})^{3}$ & 317 [162-764] & 235 [118-629] & 0.063 \\
\hline
\end{tabular}

Note: ${ }^{1}, t$-test; ${ }^{2}$, chi-square test; ${ }^{3}$, Mann-Whitney $\mathrm{U}$ test; ${ }^{4}$, Fisher's exact test. 
FUO patients routinely undergo chest and abdominal radiographic, bone marrow needle biopsy, and immune function examinations. Consequently, connective tissue diseases and neoplastic diseases in this study were diagnosed quickly in the majority of cases. Many patients with FUO are unable to identify the cause of the disease through systematic examination, but they can be cured according to the experience of using drugs. Such treatment can be called diagnostic treatment.

Tuberculosis is the most common of all infectious diseases that cause FUO. A large number of tuberculosis patients are not diagnosed by pathogenic investigation but are diagnosed based on effective diagnostic anti-tuberculosis treatment. By reviewing the results of adjuvant examinations, we found that in most tuberculosis patients with long-term fever, the white blood cell count was normal or increased, the proportion of neutrophils was increased, erythrocyte sedimentation rate and C-reactive protein were increased, and the increase of procalcitonin was lower than that in patients with common bacterial infections. Through bone marrow biopsy, some other tuberculosis patients were found to have DNA fragments of mycobacterium tuberculosis, or their bone marrow smears were positive for acid-fast staining, which further attests to the importance of bone marrow biopsy for patients with FUO. As well as tuberculosis, the effective diagnosis of some other infectious diseases, such as kala-azar, also requires bone marrow biopsy.

Due to the widespread application of radiographic examination methods such as CT and MRI, FUO caused by deep abscesses has become rare; in our study, only 19 such cases were included. However, FUO caused by sepsis is still common, and special pathogens like brucellosis still exist. Therefore, patients with FUO should undergo blood culture examination during fever. When a deep abscess is present and is not easy to drain, positive blood culture can also help with the selection of appropriate antibacterial drugs.

In this study, most of the cases were diagnosed as infectious diseases, and etiological examination was done. Except for cases diagnosed as TB infection, most of them obtained positive results. They were confirmed cases. But Only a small number of 117 patients with "Septicemia" (in Table 1) were positive in blood culture, while most of them were not positive in imaging or etiology, but they were effectively treated with antibiotics, so they were empirically diagnosed as "Septicemia" or called bloodstream infection. The 19 cases of "other viral infections" failed to obtain the etiological diagnosis basis, but empirical antiviral treatment was effective, so it was diagnosed as "viral infection". It is difficult to obtain the etiological results of the above infectious diseases. We will focus on it in the future research in order to obtain a clearer diagnosis.

Among the connective tissue diseases that cause FUO, adult-onset Still's disease (AOSD) is the most common (8). By reviewing the results of adjuvant examination of cases diagnosed as AOSD, most AOSD patients were found to have significantly increased serum iron ferritin, and procalcitonin was also elevated. Procalcitonin, as an indicator of the presence of bacterial infection, has attracted an increasing amount of attention from clinicians. However, in the diagnosis of AOSD it is necessary to exclude infection, and so the increase in procalcitonin can interfere with the diagnosis. AOSD is characterized by an increased white blood cell count, mainly neutrophils. Distinguishing AOSD from bacterial infection can sometimes prove difficult. Therefore, the typical manifestations of a rash and increased ferritin levels should be afforded special attention (9). Compared with AOSD patients, ferritin in patients with bacterial infections tends to be normal or only slightly increased.

Some connective tissue diseases have positive autoantibodies, but they cannot be classified as a specific autoimmune disease. The diagnoses of undifferentiated connective tissue diseases in our hospital usually require confirmation through treatment with glucocorticoids or immunosuppressive agents.

Similar to FUO caused by deep abscesses, FUO resulting from solid tumors has become rare owing to the popularity of radiographic examination methods. Only 32 solid tumors were involved in our study, comprising $1.95 \%$ of the causes of all the cases of FUO. Hematological tumors, especially lymphoma, were the most common FUOinducing neoplastic diseases. Many cases of diffuse large B-cell lymphoma and NK/T-cell lymphoma were found in our study, and a large proportion of these were secondary to Epstein-Barr virus infection. The clinical manifestations of lymphoma are diverse. Skin lesions and nasopharynx ulcers developed in a large proportion of patients. The lymphoma patients were diagnosed by skin or mucosal biopsy. It should be noted that the bone marrow biopsy of such patients does not often return positive results. Therefore, it is necessary to pay attention to physical examinations so that any skin and mucous membrane-related lesions can be discovered, to facilitate timely biopsy. In addition to bone marrow biopsy, attention should be paid to the results of flow cytometry of bone marrow, serous membrane effusion, and peripheral blood; some bone marrow biopsies for lymphoma and multiple myeloma do not produce specific indications but can provide a diagnosis by flow cytometry. In addition, 
many patients diagnosed with lymphoma have chronic virus infection, such as EBV or CMV, which is similar to some foreign research results $(10,11)$. The pathological report of some patients directly indicated EBV associated lymphoma.

In some cases, patients with hematological tumors cannot undergo invasive examinations, such as bone marrow puncture, due to reasons including thrombocytopenia and coagulation dysfunction. Instead, they should receive routine blood tests and blood biochemical tests. Patients diagnosed with hematological malignancies have a high probability of finding abnormal cells by routine blood test; the detection of significant increase in lactate dehydrogenase and triglycerides through blood biochemical tests is indicative of a hematological tumor. Moreover, domestically and internationally, it has been reported that $66.66 \%$ of patients with non-Hodgkin lymphoma have increased lactate dehydrogenase; the increase of lactate dehydrogenase in patients with highly malignant lymphoma is greater than that in patients with low-grade malignant lymphoma $(\mathrm{P}<0.05)(12)$. Some scholars have even suggested that the level of lactate dehydrogenase could be used as an independent indicator (13) to evaluate the prognosis of patients with lymphoma. Our study also showed that lymphoma accounts for the highest proportion of neoplastic diseases that cause FUO. Accordingly, clinicians should pay more attention to a marked increase in lactate dehydrogenase.

In FUO, the clinical manifestations of lymphoma and tuberculosis are not characteristic. It is often difficult to distinguish between the two diseases, and we failed to find the clinical features and routine laboratory investigation methods for making such a distinction (Table 6). Diagnosis of lymphoma often requires pathological confirmation, but serological and pathogenic examinations can also indicate the presence of tuberculosis. This reminds clinicians to conduct tuberculosis-specific examinations (such as tuberculosis infection T-cell $\gamma$ interferon release test, PPD skin test, tuberculosis antibody test, etc.) when the cause of FUO is difficult to determine, so as to shorten the time required for diagnoses and reduce invasive examinations.

Only a small number of the 137 patients who were discharged from the hospital with undetermined causes of their FUO were seriously ill, but most were well. These patients were characterized by a long course of disease, non-suggestive adjuvant investigations, slightly increased inflammatory indicators such as blood sedimentation and C-reactive protein, and effective treatment with antiinflammatory drugs such as glucocorticoids and nonsteroidal anti-inflammatory drugs.
As mentioned above, some cases were diagnosed clinically through diagnostic treatment. Diagnostic treatment is a common method for the diagnosis of FUO. When the comprehensive auxiliary examination is still not clear about the cause of FUO, and some manifestations and examination results have some hints, it can be tried. Among them, diagnostic antituberculosis treatment is the most widely used. Many extrapulmonary tuberculosis can be clinically diagnosed through diagnostic treatment. The diagnostic treatment should be based on the treatment plan of the disease to be diagnosed. In addition to infectious diseases, non steroidal anti-inflammatory drugs and glucocorticoids are also effective in the diagnosis of suspected non-infectious inflammatory diseases, such as adult still's disease.

PET-CT has been reported at home and abroad to be of great significance to the diagnoses of causes of classic FUO that are difficult to identify $(14,15)$. In recent years, there have been reports of successful diagnosis of fever of unknown origin with PET/CT (16,17). In 2018, Kouijzer and Mulders-Manders suggested when potentially diagnostic clues are absent, PET/CT should be performed to guide additional diagnostic tests. In case of negative PET/CT and persisting $\mathrm{FUO}$, it is probably more rewarding to wait for new potentially diagnostic clues to appear than immediately perform more screening investigations (18). The diagnostic pattern of FUO is changing as time goes by, especially with the availability of non-invasive diagnostic imaging studies. However, due to the constraints of economic development in western China, few FUO patients are able to receive PET-CT examination in our hospital, and this needs to be improved in the future.

The results are different from those reported by some researchers. Some researchers believe that a large number of patients with fever of unknown origin are difficult to obtain etiological diagnosis (19). This may be caused by different diagnosis and treatment technologies in different countries, or by different criteria for etiological diagnosis. Referral of patients with fever of unknown origin to an expertise center has high diagnostic and therapeutic value, and this can significantly improve the diagnosis rate (20). In this retrospective study, some patients without etiology were diagnosed as infectious diseases through diagnostic treatment, and we classified them as cases with diagnosis. But it is not clear whether these cases will recover by themselves or by treatment. If it is included in the cases that have not been clearly diagnosed, the proportion of patients who cannot be clearly diagnosed will increase. This is also what we will study further in the future. 


\section{Conclusions}

The main causes of classic FUO are infectious diseases, among which tuberculosis accounts for the largest proportion. Non-infectious diseases that cause FUO mainly comprise connective tissue diseases and malignant tumors. AOSD accounts for many cases of connective tissue diseases that cause FUO. Meanwhile, lymphoma is the most common malignancy that causes FUO. Distinguishing between lymphoma and tuberculosis by routine examination is difficult and needs to be facilitated by tuberculosis-related serology and pathogen and pathological examinations. Clinicians should conduct detailed consultation and physical examination for classic FUO patients, and attach importance to laboratory, radiographic, pathogenic, and pathological investigations and other adjuvant methods. Through detailed clinical investigation and analyses, most cases of classic FUO can be diagnosed.

\section{Acknowledgments}

Funding: None.

\section{Footnote}

Reporting Checklist: The authors have completed the STROBE reporting checklist. Available at http://dx.doi. org/10.21037/atm-20-3875

Data Sharing Statement: Available at http://dx.doi. org/10.21037/atm-20-3875

Conflicts of Interest: All authors have completed the ICMJE uniform disclosure form (available at http://dx.doi. org/10.21037/atm-20-3875). The authors have no conflicts of interest to declare.

Ethical Statement: The authors are accountable for all aspects of the work in ensuring that questions related to the accuracy or integrity of any part of the work are appropriately investigated and resolved. This study was conducted in accordance with the Declaration of Helsinki and was approved by Ethics Committee of West China Hospital of Sichuan University. Because of the retrospective nature of the research, the requirement for informed consent was waived.

Open Access Statement: This is an Open Access article distributed in accordance with the Creative Commons Attribution-NonCommercial-NoDerivs 4.0 International License (CC BY-NC-ND 4.0), which permits the noncommercial replication and distribution of the article with the strict proviso that no changes or edits are made and the original work is properly cited (including links to both the formal publication through the relevant DOI and the license). See: https://creativecommons.org/licenses/by-nc-nd/4.0/.

\section{References}

1. Petersdorf RG, Beeson PB. Fever of unexplained origin: report on 100 cases. Medicine (Baltimore) 1961;40:1-30.

2. Durack DT, Street AC. Fever of unknown originreexmained and redefined. Curr Clin Top Infect Dis 1991;11:35-51.

3. Masashi $Y$, Yuki U, et al. Analysis of 256 Cases of Classic Fever of Unknown Origin. Intern Med 2014;53:2471-5.

4. Urdaneta V, Casadesús J. Host-pathogen interactions in typhoid fever: the model is the message. Ann Transl Med 2018;6:S38.

5. Naito T, Mizooka M, Mitsumoto F, et al. Diagnostic workup for fever of unknown origin: a multicenter collaborative retrospective study. BMJ Open 2013;3:e003971.

6. Bleeker-Rovers CP, Vos FJ, de Kleijn EM, et al. A prospective multicenter study on fever of unknown origin: the yield of a structured diagnostic protocol. Medicine (Baltimore) 2007;86:26-38.

7. Zhai YZ, Chen X, Liu X, et al. Clinical analysis of 215 consecutive cases with fever of unknown origin: A cohort study. Medicine (Baltimore) 2018;97:e10986.

8. Sipahi OR, Senol S, Arsu G, et al. Pooled analysis of 857 published adult fever of unknown origin cases in Turkey between 1990-2006. Med Sci Monit 2007;13:CR318-22.

9. Cunha BA. Fever of unknown origin (FUO): diagnostic importance of serum ferritin levels. Scand J Infect Dis 2007;39:651-2.

10. Cunha BA, Chawla K. Fever of unknown origin (FUO): $\mathrm{CMV}$ infectious mononucleosis or lymphoma? Eur J Clin Microbiol Infect Dis 2018;37:1373-6.

11. Cunha BA, Petelin A, George S. Fever of unknown origin (FUO) in an elderly adult due to Epstein-Barr virus (EBV) presenting as "typhoidal mononucleosis," mimicking a lymphoma. Heart Lung 2013;42:79-81.

12. Benborbker L, Valat C, Linassier C, et al. A new serologic index for low-grade non-Hodkin's lymphom a based on initial CA125 and LDH serum level. Annoncol 
2000;11:185-91.

13. Shipp M, Harringtin D, Anderson J, et al. A predictive model for aggresivelymphoma: the intermational NHL prognostic factors project. N Engl Med 1993;3:987.

14. Bleeker-Rovers CP, Vos FJ, Mudde AH, et al. A prospective multi-centre study of the value of FDG-PET as part of a structured diagnostic protocol in patients with fever of unknown origin. Eur J Nucl Med Mol Imaging 2007;34:694-703.

15. Meller J, Altenvoerde G, Munzel U, et al. Fever of unknown origin: prospective comparison of (18F) FDG imaging with a double-head coincidence camera and gallium-67 citrate SPET. Eur J Nucl Med 2000;27:1617-25.

16. Mujukian A, Kay M, Marks JL. Symptomatic lower limb large vessel vasculitis presenting as fever of unknown origin diagnosed on FDG-PET/CT. BMJ Case Rep 2018;2018:bcr2017224019.

Cite this article as: Zhou G, Zhou Y, Zhong C, Ye H, Liu Z, Liu Y, Tang G, Qu J, Lv X. Retrospective analysis of 1,641 cases of classic fever of unknown origin. Ann Transl Med 2020;8(11):690. doi: 10.21037/atm-20-3875
17. Liu $W$, Jiang $H$, Jing $H$, et al. An unusual cause of fever of unknown origin with enlarged lymph nodes-relapsing polychondritis: A case report. Medicine (Baltimore) 2017;96:e8734.

18. Kouijzer IJE, Mulders-Manders CM, Bleeker-Rovers CP, et al. Fever of Unknown Origin: the Value of FDG-PET/ CT. Semin Nucl Med 2018;48:100-7.

19. Mulders-Manders CM, Engwerda C, Simon A, et al. Long-term prognosis, treatment, and outcome of patients with fever of unknown origin in whom no diagnosis was made despite extensive investigation: A questionnaire based study. Medicine (Baltimore) 2018;97:e11241.

20. Mulders-Manders CM, Pietersz G, Simon A, et al. Referral of patients with fever of unknown origin to an expertise center has high diagnostic and therapeutic value. QJM 2017;110:793-801. 